\title{
Pemberdayaan wanita Kelompok Serba Usaha Srikandi melalui diversifikasi produk kopi bubuk herbal
}

\author{
Maria Erna Kustyawati ${ }^{1 *}$, Ribut Sugiharto ${ }^{1}$, Sri Waluyo ${ }^{2}$, dan Erlina ${ }^{3}$ \\ ${ }^{1} J u r u s a n$ Teknologi Hasil Pertanian, Fakultas Pertanian, Universitas Lampung \\ 2Jurusan Teknologi Pertanian, Fakultas Pertanian, Universitas Lampung \\ ${ }^{3} J u r u s a n$ Manajemen, Fakultas Ekonomi dan Bisnis, Universitas Lampung
}

\section{*mariaernakustyawati@gmail.com}

\begin{abstract}
The community service was aimed to improve the quality and enhance the marketing of ground coffee owned by Business Group of Srikandi (KSU Srikandi), a group of women coffee farmers located in Sidorejo, Pekon Ngarip, Ulu Belu Subdistrict, Tanggamus Regency of Lampung. KSU Srikandi has produced ground coffee since 2015. However, the group has problems on limited market and low quality of coffee beans. The community services have been done to overcome the issues. The actions are counselling, demonstrations on constructing production house to enhance the sanitizing program, labelling system, and achieving household industrial food production certificate (P-IRT). The result indicated that the production increase $19.1 \%$ in a month due to the labelling system, achievement of P-IRT, and construction of production house, which enhanced sanitizing, staff coordination, and direct product selling. Also, product development of ground coffee with cinnamon aroma helped to expand the market. In the future, KSU Srikandi hopes to make the coffee plantation area and its ground coffee products become a tourism coffee spot.
\end{abstract}

Abstrak Kegiatan pengabdian masyarakat ini bertujuan untuk meningkatkan mutu dan pemasaran kopi bubuk Kelompok Serba Usaha (KSU) Srikandi di Dusun Sidorejo Pekon Ngarip Kecamatan Ulu Belu Kabupaten Tanggamus, Lampung. Srikandi adalah kelompok wanita petani kopi yang mempunyai usaha kecil membuat kopi bubuk murni sejak tahun 2015. Namun, hingga kini mutu kopi masih rendah begitu juga dengan pemasarannya. Penyuluhan dan demonstrasi tentang pelabelan, sanitasi proses produksi, pentingnya izin produksi sebagai solusi dari Tim pelaksana. Anggota kelompok Srikandi mengikuti pelaksanaan program dengan baik untuk peningkatan usaha mereka. Saat ini produksinya meningkat $19,1 \%$ dalam sebulan dengan adanya label kemasan, dan perolehan izin produksi P-IRT. Rumah produksi telah dimiliki untuk meningkatkan sanitasi proses produksi sekaligus tempat penjualan kopi bubuk dankoordinasi anggota semakin intensif. Dalam upaya menciptakan pasar baru KSU Srikandi membuat kopi bubuk herbal dengan aroma kayumanis. Kopi herbal mempunyai khasiat menyehatkan dengan adanya kayumanis disamping sebagai penyegar. Kedepan KSU Srikandi berharap dapat menjadikan area kebun kopi dan produk kopi bubuknya menjadi wisata kopi karena rumah produksi dapat berfungsi sebagai singgah bagi pengunjung di Ulu Belu.

Keywords: herbal coffee; women empowerment; coffee tourism; coffee powder

\section{¿ OPEN ACCESS}

Citation: Kustyawati, M.E., R. Sugiharto, S Waluyo, \& Erlina. 2019. Pemberdayaan wanita Kelompok Serba Usaha Srikandi melalui diversifikasi produk kopi bubuk herbal. Riau Journal of Empowerment 2(1): 15-20 https://doi.org/10.31258/raje.2.1.13

Received: 2018-09-11 Revised: 2019-05-22 Accepted: 2019-05-28

Language: Bahasa Indonesia (id)

Funding: Terimakasih kepada Kementerian Riset, Teknologi dan Pendidikan Tinggi yang mendanai program Pengabdian Kepada Masyarakat Skim Hi-Link Tahun Anggaran 2018

(C) 2019 Maria Erna Kustyawati et al. The article by Author(s) is licensed under a Creative Commons Attribution 4.0 International License. This license permits unrestricted use distribution, and reproduction in any medium, provided the original author and source are credited. 


\section{PENDAHULUAN}

Hasil pendampingan program Pengabdian Kepada Masyarakat oleh Kustyawati dkk. (2017) dan Setyani dkk. (2015), Mitra Kelompok Serba Usaha (KSU) Srikandi telah melaksanakan proses penyangraian dengan benar sehingga menghasilkan produk kopi sangrai dan kopi bubuk dengan warna kayu manis dari yang warna hitam pada produk sebelumnya, melaksanankan pelatihan untuk perolehan P-IRT yang dilaksanakan oleh Dinas Kesehatan Tanggamus, melaksanakan proses penyosohan dan pengolahan yang benar dengan nara sumber dari Universitas Lampung dan Pemerintah Daerah Tanggamus, telah menerapkan personal higien selama proses pengolahan, mengikuti pelatihan Pembukuan Wanita Pedesaan se Asia yang diselenggarakan oleh WWF, terjadi peningkatan produksi $20 \%$ dengan meningkatkan jejaring melalui pameran produk Dies Universitas Lampung 25 September 2017, dan Hari Kopi se-Dunia 30 Oktober 2017. Dalam upaya perbaikan sanitasi dan higienitas proses produksi, telah dimulai didirikan rumah Produksi Kopi bubuk dengan kerjasama anggota KSU Srikandi dan Tim Hi-Link. Pembangunan ini telah mencapai $40 \%$ saat artikel ini ditulis. Kelompok usaha tani Srikandi berada di Pekon Ngarip, kecamatan Ulu Belu kabupaten Tanggamus berdiri pada tahun 2016. Kelompok tani ini mempunyai usaha kopi bubuk, mempunyai anggota 63 orang yang diketuai oleh Sri Wahyuni. Kelompok usaha Srikandi telah rutin memproduksi kopi bubuk $30 \mathrm{~kg} / \mathrm{minggu}$ atau $500 \mathrm{~kg} / \mathrm{bulan}$. Bahan baku berasal dari anggota kelompok. Pengolahan kopi bubuk dilakukan oleh anggota dengan masing-masing pembagian tugas yang dikoordinir oleh koordinator yaitu Santi.

Proses produksi kopi bubuk meliputi: penjemuran kopi gelondong di lantai tanah, buah kopi kering setelah penjemuran rata-rata 10 hari, kemudian dilakukan pelepasan kulit dalam mesin Huller, yang diletakkan kira-kira $10 \mathrm{~m}$ dari rumah produksi. Kopi lepas kulit selanjutnya proses pencucian dan dijemur kembali sekedar untuk menghilangkan air, dan masuk dalam mesin penyangrai berkapasitas $15 \mathrm{~kg}$, selama kurang lebih 15 menit karena suhu yang tidak terkontrol. Kopi sangrai dikering anginkan dalam tampak anyaman bamboo dan selanjutnya masuk dalam mesin penepung berkapasitas $5 \mathrm{~kg}$. Kopi bubuk ditampung dalam ember plastik, dan siap dikemas dalam plastik bermerek Srikandi kemudian disegel secara manual. Pemasaran kopi bubuk di sekitar desa dan men-supply kebutuhan karyawan Pertamina. Kebun kopi di Kecamatan Ulu Belu seluas 9.083 hektar dengan 79 kelompok tani.

Program Hi-Link sasarannya adalah pemenuhan kebutuhan semua anggota kelompok petani kopi di Pekon Ngarip untuk dapat mengolah kopi hasil panennya menjadi kopi beras Grade dan mengolah kopi beras menjadi kopi bubuk dengan standar nasional maupun internasional. Pendirian rumah industri kopi bubuk diharapkan mampu mengatasi kesulitan masyarakat akan sarana produksi kopi beras maupun kopi bubuk untuk menjamin kontinuitas produksi. Target jangka panjang dengan telah tersedianya rumah industri kopi bubuk dengan produksi yang bermutu dapat mendukung wacana Wisata Kopi di Pekon Ngarip, yang mana wisata kopi tersebut telah dirintis oleh anggota kelompok.

\section{MASALAH}

Kelompok usaha pengolahan kopi bubuk Srikandi mempunyai permasalahan pada pemasaran yang masih rendah dan jangkauan pemasaran juga masih sempit, dan proses produksi yang belum saniter. Sementara itu, pengemasan yang dilengkapi dengan pelabelan yang sesuai kaidah pelabelan sangat diperlukan. Izin usaha produksi rumah tangga diperlukan untuk memperluas jangkauan pemasaran, dan perlu adanya rumah produksi untuk menjaga siniter dan higienis produksi. Berdasarkan hal tersebut, (1) KSU Srikandi belum memahami secara jelas kaidah pelabelan, (2) pemahaman tentang perlunya perizinin industri rumah tangga (PIRT), (3) tata letak peralatan produksi dalam area produksi belum dipahami; (4) KSU Srikandi belum mengetahui cara membuat kopi herbal beraroma kayumanis.

\section{METODE}

Metode yang digunakan adalah (1) ceramah mengenai prinsip dan kaidah pelabelan yang benar, tata letak peralatan produksi sesuai fungsi dan keamanan, dan manfaat memiliki P-IRT 
serta cara mendapatkannya, serta cara memproduksi kopi herbal. Ceramah menggunakan makalah yang disampaikan dalam bentuk power point dan proyektor di balai Pekon., (2) mengadakan diskusi dan Tanya jawab tentang materi yang telah diberikan., (3) demonstrasi cara mendesign label dan meletakkan label pada wadah kemasan, (4) demonstrasi perbandingan herbal dengan kopi bubuk dan cara mengolahnya., (5) peletakan peralatan produksi dalam rumah produksi., (6) monitoring secara berkala oleh Tim Pelaksanan dilakukan dengan site visit ke lokasi rumah produksi satu bulan sekali.

Populasi penerapan melibatkan 12 orang anggota kelompok Srikandi. Pengambilan sampel untuk mengetahui partisipasi anggota dilakukan secara purposive random sampling, dan data yang dikumpulkan merupakan data primer yang diperoleh dari sampel dengan berpedoman pada kuisioner yang telah disiapkan. Pengumpulan data dilakukan pada saat kegiatan penyuluhan, berapa jumlah yang menghadiri dan respon terhadap materi yang diberikan. Demikian juga data ketika demonstrasi plot, keikutsertaan anggota membuat design label, membuat kopi herbal dan menata alat produksi.

\section{PEMBAHASAN}

\section{Tingkat partisipasi anggota dalam penerapan teknologi}

Partisipasi anggota dalam suatu program menjadi salah satu faktor utama yang menentukan keberhasilan program yang sedang dilaksanakan (Lugiarti, 2004). Dalam program pemberdayaan, partisipasi merupakan unsur pokok dan sebagai langkah penting dalam upaya memberdayakan satu masyarakat atau kelompok. Pada program ini partisipasi adalah keikutsertaan anggota kelompok usaha Srikandi dalam pengembangan kemampuannya intelektual dan finansialnya.

\section{Penyuluhan materi teknologi pelabelan, izin produksi, dan pencampuran kopi herbal}

Berdasarkan hasil pendampingan pada kelompok Srikandi, tingkat partidipasi yang tinggi adalah waktu penyuluhan materi teknologi yang dilakukan pada pagi hingga siang hari karena mereka mempunyai jam kerja pada industrinya adalah pagi hingga siang hari. Kegiatan penyuluhan dilakukan empat kali sesuai dengan jenis materi. Jumlah kehadiran dibuat ratarata setiap kehadiran. Dari hasil kegiatan ini dapat dikatakan bahwa secara umum anggota kelompok Srikandi antusias terhadap peningkatan ilmu pengetahuan dalam materi karena bersentuhan langsung dengan tujuan usaha mereka yaitu untuk meningkatkan produksi dan pemasaran.

Tabel 1. Pelaksanaan kegiatan dan evaluasi penerapan teknologi pelabelan dan pencampuran kopi herbal dalam upaya meningkatkan pemasaran

\begin{tabular}{cccccc}
\hline No. & \multicolumn{1}{c}{ Jenis kegiatan } & \multicolumn{1}{c}{ Program } & Evaluasi & Kehadiran & Persentase \\
\hline 1 & Sosialisasi program & $\begin{array}{l}\text { Kegiatan } \\
\text { Penyuluhan tentang } \\
\text { prinsip design label dan } \\
\text { proporsi dengan wadah } \\
\text { kemasan. }\end{array}$ & Tinggi & 15 & 100 \\
Pelabelan & & Tingi & 12 & 80 \\
3 & $\begin{array}{l}\text { Penyuluhan tentang } \\
\text { manfaat dan cara } \\
\text { rumah tangga (P-IRT). }\end{array}$ & Tinggi & 12 & 80 \\
4 & Kopi herbal & $\begin{array}{l}\text { Penyuluhan tentang } \\
\text { fungsi kopi herbal dan } \\
\text { cara membuatnya. }\end{array}$ & Tinggi & 12 & 80 \\
5 & Tata letak alat produksi & $\begin{array}{l}\text { Penyuluhan tentang } \\
\text { prinsip tata letak dan } \\
\text { fungsi keamanan } \\
\text { peralatan dalam rumah } \\
\text { produksi. }\end{array}$ & Tinggi & 12 & 80 \\
& & & & \\
\hline
\end{tabular}


Tabel 1 menunjukkan bahwa minat anggota kelompok terhadap setiap kegiatan program penyuluhan adalah tinggi. Hal ini mengindikasikan bahwa ilmu pengetahuan adalah sangat penting bagi anggota kelompok. Penyuluhan merupakan cara dan salah satu upaya bagi anggota kelompok untuk meningkatan ilmu pengetahuan dan teknologi mereka, walaupun dalam masa digital teknologi ilmu pengetahuan dapat juga diperoleh melalui media sosial. Namun melalui penyuluhan oleh pakar yang sesuai merupakan cara sangat penting untuk memperoleh pengetahuan. Jika anggota kelompok mempunyai komitmen atau janji atau keikatan yang kuat terhadap suatu upaya mendapatkan ilmu pengetahuan baru, maka waktu bukan menjadi masalah bagi mereka. Oleh karena itu, mereka siap menyediakan waktunya untuk mengikuti kegiatan baik penyuluhan, demonstratsi maupun pendampingan selama program kegiatan. Waktu kegiatan dilaksanakan pada pagi hingga siang hari waktu jam kerja anggota sebagai pengelola dan pelaku usaha. Partisipasi yang tinggi apabila suatu masyarakat atau sekumpulan anggota masyarakat merasa informasi baru yang diterima sangat penting dalam meningkatkan ilmu pengetahuan mereka.

\section{Pelabelan}

Peraturan pelabelan produk pangan olahan menurut Badan Pengawasan Obat dan Makanan (2014), mengenai ketentuan label dan iklan, bahwa masyarakat perlu mendapatkan informasi yang jelas mengenai setiap produk pangan yang dikemas. Informasi tersebut terkait dengan asal, keamanan, mutu, kandungan gizi, dan keterangan lain. Tujuan pelabelan dan iklan adalah agar masyarakat dapat memilih dan terwujudnya fair trade. Badan POM menyebutkan ketentuan umum pelabelan mencakup (1) pangan olahan dalam kemasan eceran wajib memiliki surat persetujuan pendaftaran (MD/ML), (2) dikecualikan untk pangan olahan bahwa: (a) diproduksi oleh industry rumah tangga (menunjukkan SP-PIRT), (b) masa simpan kurang dari 7 hari pada suhu kamar, (c) dimasukkan ke dalam wilayah Indonesia dalam jumlah kecil untuk keperluan (1) sampel dalam rangka permohonan pendaftaran, (2) penelitian, (3) konsumsi sendiri., (d) digunakan lebih lanjut sebagai bahan baku dan tidak dijual secara langsung kepada konsumen akhir.

Prinsip Pelabelan bahwa:

1. Harus benar dan tidak menyesatkan

2. Wajib ada pada setiap pangan terkemas

3. Tidak mudah lepas, luntur atau rusak

4. Berisi keterangan mengenai pangan

Proporsi label bahwa:

1. Mempunyai bagian utama label dengan area lebih kurang 2/3 bagian label, berisi nama produk, nama dagang, saran penyajian, halal, nama dan alamat produsen, isi bersih, nomor pendaftaran.

2. Bagian lain yaitu $1 / 3$ bagian label memuat: komposisi, cara penyiapan/penggunaan, kode produksi (nomor dan masa simpan).

3. Format nilai gizi: bisa di bagian halaman balik label.

Paga Gambar 1 menajikan produk kemasan dan pelabelan yang dihasilkan pada kegiatan yang telah mengikuti kaidah pelabelan Badan POM. Seritifikat P-IRT yang diperoleh KSU Srikandi dalam pembinaan oleh Tim pelaksana.

\section{Perluasan jangkauan pemasaran}

Dalam upaya meningkatkan pemasaraan, kegiatan difokuskan pada pengemasan dan pelabelan. Hal ini dapat dijelaskan bahwa bagi suatu unit usaha baik kecil maupun sebuah perusahaan kemasan mempunyai arti yang sangat penting karena dengan kemasan suatu unit usaha dapat menarik minat pembeli dalam melakukan keputusan pembelian atas produk yang dimaksud (Susetyarsi, 2014). Bahan kemasan, betuk kemasan dan pelabelan merupakan tiga rangkaian variabel kemasan yang tidak dapat dipisahkan. Ketiga variabel tersebut berpengaruh signfikan terhadap keputusan pembelian. Oleh karena itu, pengetahuan kegiatan pengemasan dan pelabelan dalam program pengabdian ini sebagai solusi yang sangat tepat dalam meningkatkan produksi dan pemasaran. 


\section{Sanitasi}

Pentingnya sanitasi untuk diimplementasikan /diterapkan dalam produksi kopi bubuk dengan memperhatikan beberapa faktor antara lain bahwa sanitasi merupakan salah satu aspek yang menentukan mutu produk akhir dari suatu industry pangan, disamping dapat mengurangi resiko kontaminasi mikroorganisme, dan meminimalisir terjadinya keracunan, sehingga kerusakan produk dapat dicegah (Sela, 2017). Rumah produksi pada Gambar 1 sebagai salah satu upaya perbaikan sanitasi pada proses produksi kopi bubuk oleh Tim Pelaksanan, mengingat terdapat dua hal yang menentukan suatu ruang produksi saniter adalah konstruksi dan tata letak (Direktorat Pengolahan Hasil Pertanian Ditjen Pengolahan dan Pemasaran Hasil Peranian, 2009).

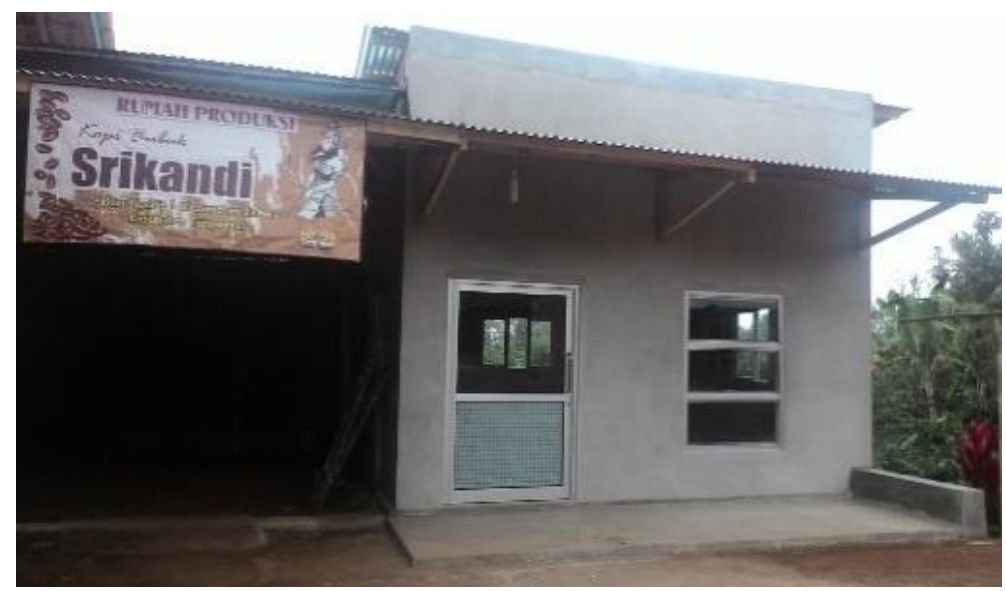

Gambar 1 Rumah produksi

\section{Kopi Herbal}

Kopi herbal merupakan salah satu produk diversifikasi produk olahan kopi bubuk yang dicampur dengan herbal dengan tujuan memperoleh aroma dan citarasa serta fungsional baru yang lebih baik tanpa mengurangi rasa minuman kopi tersebut. Kopi kayu manis mempunyai kelebihan yaitu meningkatkan penghambatan proses oksidasi sehingga berpotensi sebagai sumber antioksidan alami (Rohmah, 2010), karena adanya senyawa eugenol yang berasal dari kayumanis. Gambar 2 menyajikan kemasan kopi bubuk kayumanis yang diproduksi KSU Srikandi dengan binaan oleh Tim Pelaksana.

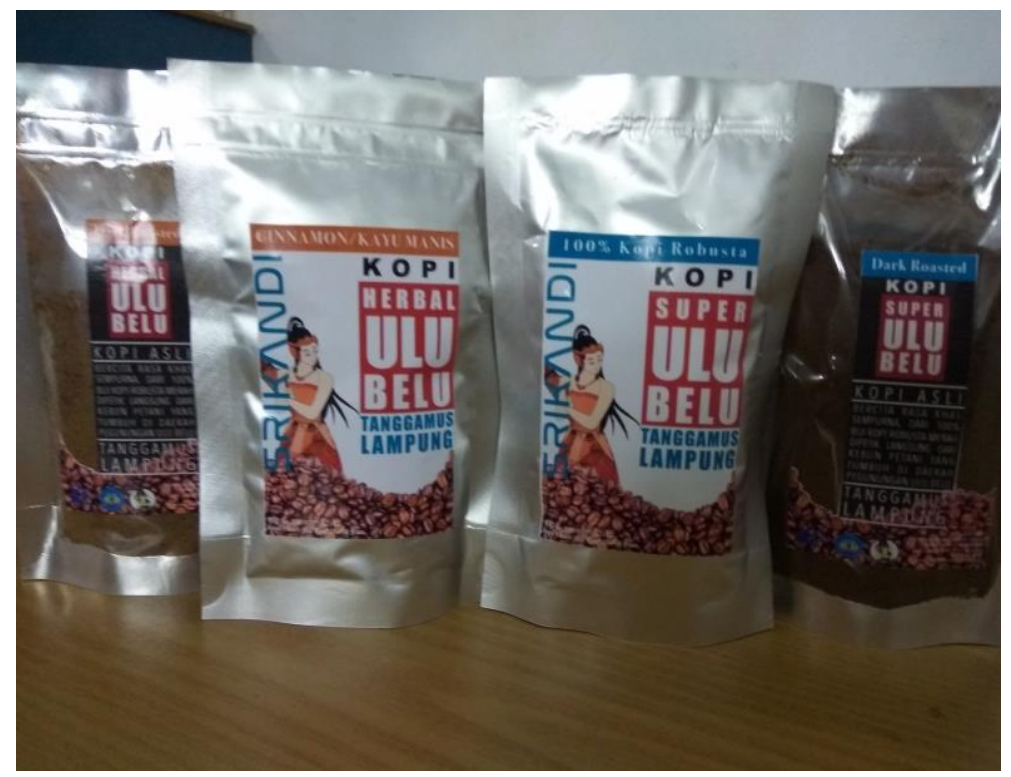

Gambar 2 Kemasan dan pelabelan 


\section{KESIMPULAN}

Pemberdayaan wanita tani kopi pada kelompok serba usaha Srikandi melalui desiminasi teknologi pada peningkatan produksi dan diversifikasi kopi bubuk herbal berhasil baik yang diindikasikan oleh tingkat partisipasi anggota kelompok. Program kegiatan pengabdian kepada masyarakat ini meningkatkan produksi kopi bubuk dan pemasarannya dengan adanya pelabelan yang memuat perizinan P-IRT, dan varian kopi herbal, serta berdirinya rumah produksi.

\section{UCAPAN TERIMAKASIH}

Ucapan terimakasih kepada Kementerian Riset, Teknologi dan Pendidikan Tinggi yang mendanai program Pengabdian Kepada Masyarakat Skim Hi-Link Tahun Anggaran 2018. LPPM Universitas Lampung, Fakultas Pertanian Universitas Lampung, Dinas UMKM Pemda Tanggamus, dan KSU Srikandi.

\section{Daftar Pustaka}

1. Badan Pengawasan Obat dan Makanan, NA-DFC. 2014. Peraturan Pelabelan Produk Pangan Olahan, Workshop Home Fortification, 8-5-2014.

2. Direktorat Pengolahan Hasil Pertanian Ditjen Pengolahan dan Pemasaran Hasil Peranian. 2009. Konsep Pedoman Sanitasi dan Hygiene Agroindustri Pedesaan. Jakarta: Departemen Pertanian.

3. Kustyawati, M.E., S. Setyani, R. Sugiharto, dan S. Waluyo. 2017. Produksi kopi bubuk terintegrasi untuk meningkatkan mutu pada Kelompok Serba Usaha Srikandi di Kabupaten Tanggamus. Batoboh 2(1): 45-56. http://doi.org/10.26887/bt.v2i1.346

4. Lugiarti, E. 2004. Peningkatan partisipasi masyarakat dalam proses perencanaan program pengembangan masyarakat di Komunitas Desa Cijayanti. Tesis Program Magister. Institut Pertanian Bogor.

5. Rohmah, M. 2010. Aktifitas antioksidan campuran kopi Robusta (Coffea cannephora) dengan kayu manis (Cinnamomun burmanii). Jurnal Teknologi Pertanian Universitas Mulawarman 6(2): 50-54.

6. Sela, R. 2017. Implementasi sanitasi pangan pada produksi kopi di PT Perkebunan Nusantara IX Jambu Semarang. http://repository.unika.ac.id/14593/1/14.I1.0174\%20Roswita\%20Sela.pdf Diakses pada 5 Agustus 2018.

7. Setyani, S., Susilawati, dan A.S. Zuidar. 2015. Laporan Pengabdian Ibm Kopi di Tanggamus. Lampung: Universitas Lampung.

8. Susetyarsi, T.H. 2014. Kemasan produk ditinjau dari bahan kemasan, bentuk kemasan dan pelabelan pada kemasan pengaruhnya terhadap keputusan pada produk minuman Mizone di Kota Semarang. Jurnal STIE Semarang 4(3): 2252-7826 